\title{
Experimental Study on Performance in Submerged Membrane Granular-Like Sludge Bioreactors for Biopharmaceutical Wastewater Treatment
}

\author{
Yuanyang Zhang ${ }^{1 *}$, Dongen Chen ${ }^{2}$ \\ ${ }^{1}$ Department of Environmental and Chemical Engineering, Tangshan University, Tangshan 063000, China \\ ${ }^{2}$ Tianjin Yao Tech Co., Ltd, Tianjin 300459, China
}

Received: 23 March 2021

Accepted: 17 June 2021

\begin{abstract}
The granular-like aerobic sludge was quickly prepared through firstly three weeks cultivating the activated sludge in tank with synthetic wastewater and then one month in airlift sequencing batch reactor (SBR) with real biopharmaceutical wastewater by reasonably optimizing operation parameters based on the variation of sludge volume index (SVI). Concentrations of chemical oxygen demand (COD) and $\mathrm{NH}_{4}^{+}-\mathrm{N}$ of the wastewater fed to submerged membrane bioreactors (SMBRs) were around $1030 \mathrm{mg} / \mathrm{L}$ and $60 \mathrm{mg} / \mathrm{L}$, respectively. Experimental results showed the residual of COD, $\mathrm{NH}_{4}^{+}{ }^{+} \mathrm{N}, \mathrm{NO}_{2}{ }^{-}-\mathrm{N}$ and $\mathrm{NO}_{3}^{-}-\mathrm{N}$ for the acclimated activated sludge $\mathrm{SMBR}$ was $30 \sim 60 \mathrm{mg} / \mathrm{L}, 0.5 \sim 1.2 \mathrm{mg} / \mathrm{L}$, 0 , and $0.8 \sim 2.0 \mathrm{mg} / \mathrm{L}$, while for the granular-like aerobic sludge SMBR was only $0 \sim 1.0 \mathrm{mg} / \mathrm{L}$, $0 \sim 0.2 \mathrm{mg} / \mathrm{L}, 0$, and $0 \sim 0.03 \mathrm{mg} / \mathrm{L}$, typical analytical data also showed that the removal efficiencies of total nitrogen (TN) and total phosphorous (TP) were $32.86 \%, 99.52 \%$ and $17.54 \%, 77.68 \%$ for acclimated activated sludge and granular-like aerobic sludge SMBR systems, respectively. It also did not show obvious stratification or crush of the granular-like aerobic sludge in SMBR with a size of $0.5 \sim 0.8 \mathrm{~mm}$ during the operation. The stability under continuous operation in SMBRs showed that the permeate flux with acclimated activated sludge rapidly declined by about $50 \%, 70 \%$ and $90 \%$ when operation around $30 \mathrm{~h}, 150 \mathrm{~h}$ and $320 \mathrm{~h}$, while the granular-like aerobic sludge system was quite stable. SEM observation indicated that the surface of membrane used in SMBR with the granular-like aerobic sludge was almost the same with the fresh membrane, while the surface of membrane used in SMBR with acclimated activated sludge clearly reflected the relative quantities of the different foulants on the membrane.
\end{abstract}

Keywords: SBR, SMBRs, aerobic granules, biopharmaceutical wastewater

*e-mail: yyzhang90@126.com 


\section{Introduction}

Environmental deterioration together with the need for water reuse and the increasingly restrictive legislation of water quality standards have led to a demand for compact, efficient and less energy consuming technologies for wastewater treatment [1, 2]. Aerobic granular sludge (AGS) and membrane bioreactors (MBRs) are two technologies with several advantages. Compared with conventional biological flocs, aerobic granules are characterized by well-defined shape and compact buildup, superior biomass retention, enhanced microbial functions, and resilient to toxicity and shock loading [3-5]. In addition, the production of sludge in the granular system is probably $0.15 \mathrm{~kg}$ total suspended solids (TSS) $\mathrm{kg} \mathrm{COD}^{-1}$ removed, while it is $0.4 \sim 0.6 \mathrm{~kg} \mathrm{TSS} \mathrm{kg} \mathrm{COD}^{-1}$ in the conventional activated sludge processes. Generally, the aerobic granular sludge system requires a much smaller footprint than the conventional activated sludge system, which favors its application in cities where space is constrained [6, 7]. The novel approach to developing fluffy biosolids into dense and compact granules offers a new dimension for wastewater treatment. However, AGS process generally requires post-treatment in order to fulfill effluent standards. MBRs integrate the biological degradation of pollutants with membrane filtration-separation during wastewater treatment. Membrane fouling, which is considered as the main process drawback, stems from the interaction between the membrane material and the (organic or inorganic) foulants, leading to membrane's efficiency deterioration [8-14]. Integrating the two technologies could be a way of combining the advantages and addressing the main problems associated with both processes [15-17].

McSwain et al. [18] indicated that the sequencing batch reactor (SBR) operation conditions obviously affected the growth of filamentous organisms and played a critical role in granule structure and composition, which showed that the protein content was $50 \%$ more in granular extracellular polymeric substances (EPS) than flocculent EPS [19, 20]. Gao et al. [21] results showed that the higher rates for chemical oxygen demand (COD) removal, nitrification and denitrification were achieved by using AGS than that with flocculent activated sludge (FAS) in the laboratory-scale SBRs. Coma et al. [22] focused on the enhancement of aerobic granulation and biological nutrient removal maintenance treating domestic wastewater. Two SBRs were inoculated with either only floccular sludge (100\%-floc SBR) or supplemented with $10 \%$ crushed granules (90\%-floc SBR), and granules developed in both reactors. The $100 \%$-floc SBR achieved $75 \%$ of nitrogen and $93 \%$ of phosphorus removal at the end of the performance, but some floccular sludge still remained in the system. The $90 \%$-floc SBR became fully granulated and finished with $84 \%$ and $99 \%$ of nitrogen and phosphorus removal, respectively. Pronk et al. [23] investigated a full-scale operation considering the granulation and performance of AGS on domestic wastewater. After a start-up period of approximately five months, a robust and stable granule bed was formed and could be maintained thereafter. The effluent from AGS system easily met the environmental requirements while the energy usage was 58 63\% lower than the average conventional activated sludge treatment plant in the local area. Campo and Bella [24] showed that the AGS directly cultivated by using petrochemical slop wastewater for its treatment highlighted better total petroleum hydrocarbons (TPHs) removal efficiencies when real slop was fed to the reactors, which prompted a higher extracellular polymeric substances (EPSs) production that enhanced the bio-adsorption of TPH, thus favouring the adaptation of bacteria to hydrocarbons. Granular size would play a key role in the performance of AGS. As the diameter of the granule increases, stratification might begin to appear due to the increase in mass transfer resistance. Results showed that the medium-size granules, with a size of $0.28 \sim 0.45 \mathrm{~mm}$, were regarded as the most suitable granular size for AGS in this experiment from the perspective of denitrification and phosphorus removal [25]. Li et al. [26] results demonstrated that AGS could be cultivated in continuous-flow reactors fed with an optimized dynamic feeding condition in a modified airlift loop reactor. The fresh granules sizing $0.4 \sim 0.6 \mathrm{~mm}$ were observed in the reactors after operating two months, then turned to matured granules after another one month operation with a compact structure, a stable size of $2 \sim 4 \mathrm{~mm}$. Rajitha et al. [27] showed that the microalgae inoculated in shakeflasks could be rapidly developed into green coloured microalgae-colonized AGS and yellowed-coloured AGS, under phototrophic and non-phototrophic conditions, respectively, in which high total nitrogen and phosphate removals of $81 \sim 95 \%$ and $97 \%$, respectively, were quickly established under saline conditions. An aerobic granular sludge-based SBR performing simultaneous nitrification, denitrification and phosphorus removal (SNDPR) was evaluated with increased salinity from 1 to $2 \%(\mathrm{w} / \mathrm{v})$, results showed that the nitrogen removal performance was unaffected with increased salinity in terms of reliable and efficient nitrification and denitrification, which implied the resilience of aerobic granular sludge-based biological nitrogen and phosphorus removal processes to hypersaline stress [28]. Iorhemen et al. [29] explored AGS long-term stability at semi-pilot-scale using the combined strategy of long anaerobic slow feeding, which allowed for system stability as the reactor was operated for over eight months without any granule disintegration and high removals of COD, ammonia nitrogen $\left(\mathrm{NH}_{3}-\mathrm{N}\right)$ and TN were achieved, respectively. He et al. [30] reported that AGS for the treatment of low-strength municipal wastewater kept structural and functional resilience, while mixed carbon source largely altered and balanced the growth and competition of phosphorus/glycogen accumulating organisms (PAOs/GAOs), which could 
achieve deep-level nutrients removal through enhancing the anaerobic carbon uptake rate and strengthening the carbon usage efficiency. Gao et al. [31] investigated the effects of additional alkalinity on the performance of AGS in SBR performing SNDPR, which indicated that the additional alkalinity altered the bacterial compositions within aerobic granules at various levels and the enrichment of Thiothrix and Acinetobacter was accounted for the promotion of COD and total inorganic nitrogen (TIN) removal. We et al. [32] investigated the feasibility of aerobic granulation for the treatment of low-medium strength domestic wastewater for longterm operation and the effect of operating conditions on the properties and removal performances of the aerobic granules formed, which showed that it had good performance on total chemical oxygen demand (TCOD) and total suspended solids (TSS) removal, respectively. In addition, the operating conditions would have effects on its performance of simultaneous nitrification and denitrification (SND) removal efficiency.

$\mathrm{Ji}$ and Zhou [33] showed that the composition of EPS and sludge flocs attached to the membranes depended on the composition of the mixed liquor and membrane hydrophobicity, which strongly influenced membrane fouling. Li et al. [34] demonstrated that the aerobic granular sludge membrane bioreactor (AGS-MBR) a stable removal of carbon and nitrogen examined systemically over four months for synthetic wastewater and municipal sewage treatment, respectively. The membrane fouling propensity was apparently lower in AGS-MBRs with no membrane cleaning during the operation, which showed that AGS-MBR could be effective and stable for municipal sewage treatment and reuse during long-term operation. A full detailed design for potential application has been made based on granular sludge sequencing batch reactors (GSBRs), which showed that from a sensitivity analysis it appeared that the combination of GSBRs with MBRs would be an attractive technology [35]. Wang et al. [36] compared the effects of activated sludge with aerobic granule on its fouling of the forward osmotic membrane bioreactors (FOMBRs). It indicated that the content of the soluble microbial products (SMP) in reactor with activated sludge was generally higher than that in reactor with aerobic granule, which resulted in more polysaccharides and proteins in the fouling layer of the membrane with activated sludge, while the membrane surface with aerobic granule was mainly Proteobacteria and Firmicutes with better salt tolerance. It is believed that the combination of aerobic granules with MBR operation could possibly eliminate or at least reduce the flocculated sludge concentration, which could consequently offer the possibility of alleviating membrane fouling. However, few papers have been published so far provide much information on key issues such as the effects of important operating parameters, e.g. feeding, aeration rate, recycling, and discharging on the performance of submerged membrane granular sludge bioreactors (SMGSBRs).
This study provided information about aerobic granules formation in SBRs with airlift and characterization of the activated sludge and aerobic granules. The membrane permeate fluxes in the submerged conditions were determined and compared by using activated sludge and aerobic granules, respectively. The stability of membrane permeate flux was also assessed, which would provide the basis for further investigations of submerged membrane granular sludge bioreactor in a pilot-scale.

\section{Material and Methods}

\section{Materials}

The activated sludge used for cultivating aerobic granules was collected from the secondary sedimentation tank in a local water reclamation plant, which was washed several times and the upper float and lower sediment was filtered out. In order to produce the desired aerobic granules, synthetic wastewater was firstly used to cultivate the activated sludge for several days to make it better adapt the used environment, and then wastewater collected from a local biopharmaceutical plant was used to continue cultivating process. The following compositions from Sinopharm were used to cultivate activated sludge and aerobic granules, sodium acetate (AR, $\geq 99.0 \%$ ), ammonium chloride (GR, $\geq 99.8 \%$ ), magnesium sulfate (AR, $\geq 99.0 \%$ ), potassium dihydrogen phosphate (AR, $\geq 99.5 \%$ ), dipotassium hydrogen phosphate (AR, $\geq 98.0 \%$ ), ferrous sulphate (AR, $\geq 99.0 \%$ ), and calcium chloride (AR, $\geq 99.0 \%$ ). Analysis results indicated that the typical contents of $\mathrm{COD}, \mathrm{NH}_{4}^{+}-\mathrm{N}, \mathrm{TN}$ and $\mathrm{TP}$ of the wastewater sample collected from a local biopharmaceutical plant were 1000 1300 $\mathrm{mg} / \mathrm{L}$, 40 80 $\mathrm{mg} / \mathrm{L}, \quad 90 \sim 130 \mathrm{mg} / \mathrm{L}$, and $25 \sim 30 \mathrm{mg} / \mathrm{L}$, respectively. The flat sheet membranes of polyvinylidene fluoride (PVDF) provided by Sinochem (China) were used to assess the performance of the membrane bioreactor system, in which the effective surface area of each membrane module was $120 \mathrm{~cm}^{2}$. The membranes were firstly pretreated with 600 800 ppm sodium hypochlorite (CP, Sinopharm), then soaked in the deionized water (Merck Millipore, Germany) for two hours, and stored for usage in refrigerator.

\section{Analytical Methods}

The mixed liquor suspended solids (MLSS) and chemical oxygen demand (COD) were determined following the Standard Methods (APHA 1998). The total organic carbon (TOC) was determined by using the analyzer (XPERT-TOC/TN ${ }_{b}$, The Netherlands). The content of TN and TP of the treated wastewater was analyzed by the spectrophotometry of UV-2102PCS (Triple Quad Technologies Co., Ltd., Shanghai, China). 


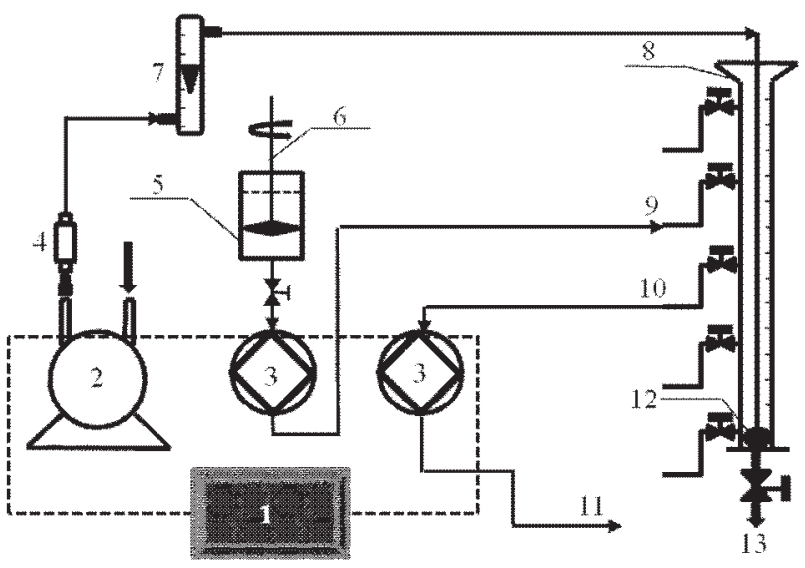

Fig. 1. A diagram of SBRs for cultivating aerobic granular-like sludge.

1-timer ,2-air pump, 3-suction pump, 4-purifier, 5-substrate container, 6-stirrer ,7-flow meter 8-airlift reactor, 9-substrate inlet, 10-upper float exit, 11-discharge, 12-air distributor, 13-discharge.

The ammonia nitrogen $\left(\mathrm{NH}_{4}^{+}-\mathrm{N}\right)$ in the wastewater was determined by Nessler's reagent spectrophotometry (National Environmental Protection Standards, China). The $\mathrm{NO}_{2}^{-}-\mathrm{N}$ and $\mathrm{NO}_{3}^{-}-\mathrm{N}$ concentration of the wastewater in submerged membrane bioreactors and effluent from membrane filtration was determined by liquid chromatography (LC-10A $\mathrm{vp}$, Shimadz, Japan), respectively. The size distribution of activated and granule sludge was determined with a particle size analyzer (MASTERSIZER 2000, England). Granule and membrane structures were determined by scanning electron microscope (SEM) (JSM-35C, Japan), respectively. An image analyzer (Olympus SZX12, Japan) was also used to observe the morphology of activated and aerobic granule sludge.

\section{Setups}

The systems applied in this study consisted of sequencing batch reactors (SBRs, Fig. 1) used for granulation of aerobic activated sludge and submerged membrane bioreactors (SMBRs, Fig. 2), respectively. The initial activated sludge used to cultivate granularlike aerobic sludge was collected from a local water reclamation plant, which was put into a plastic bucket (tank) with air aeration lasted for several days by using the following composition of synthetic wastewater, the concentration of sodium acetate, ammonium chloride, magnesium sulfate, potassium dihydrogen phosphate, dipotassium hydrogen phosphate, ferrous sulphate and calcium chloride was $2.80 \mathrm{~g} / \mathrm{L}, 0.18 \mathrm{~g} / \mathrm{L}, 0.02 \mathrm{~g} / \mathrm{L}$, $0.01 \mathrm{~g} / \mathrm{L}, 0.02 \mathrm{~g} / \mathrm{L}, 0.01 \mathrm{~g} / \mathrm{L}$ and $0.01 \mathrm{~g} / \mathrm{L}$, respectively. After that, certain amount of activated sludge in the bucket was collected and washed several times. The upper float was filtered out and the bottom was transferred to SBR systems in order to cultivate the granular-like aerobic sludge. At beginning, SBRs were still operated by using synthetic wastewater until the mixed liquid suspended solids (MLSS) keeping relatively constant and good activated sludge volume index $\left(\mathrm{SVI} \leq 40 \mathrm{~mL} \cdot \mathrm{g}^{-1}\right)$. After that, the cultivating solution was changed from the synthetic wastewater to the wastewater collected from a local biopharmaceutical

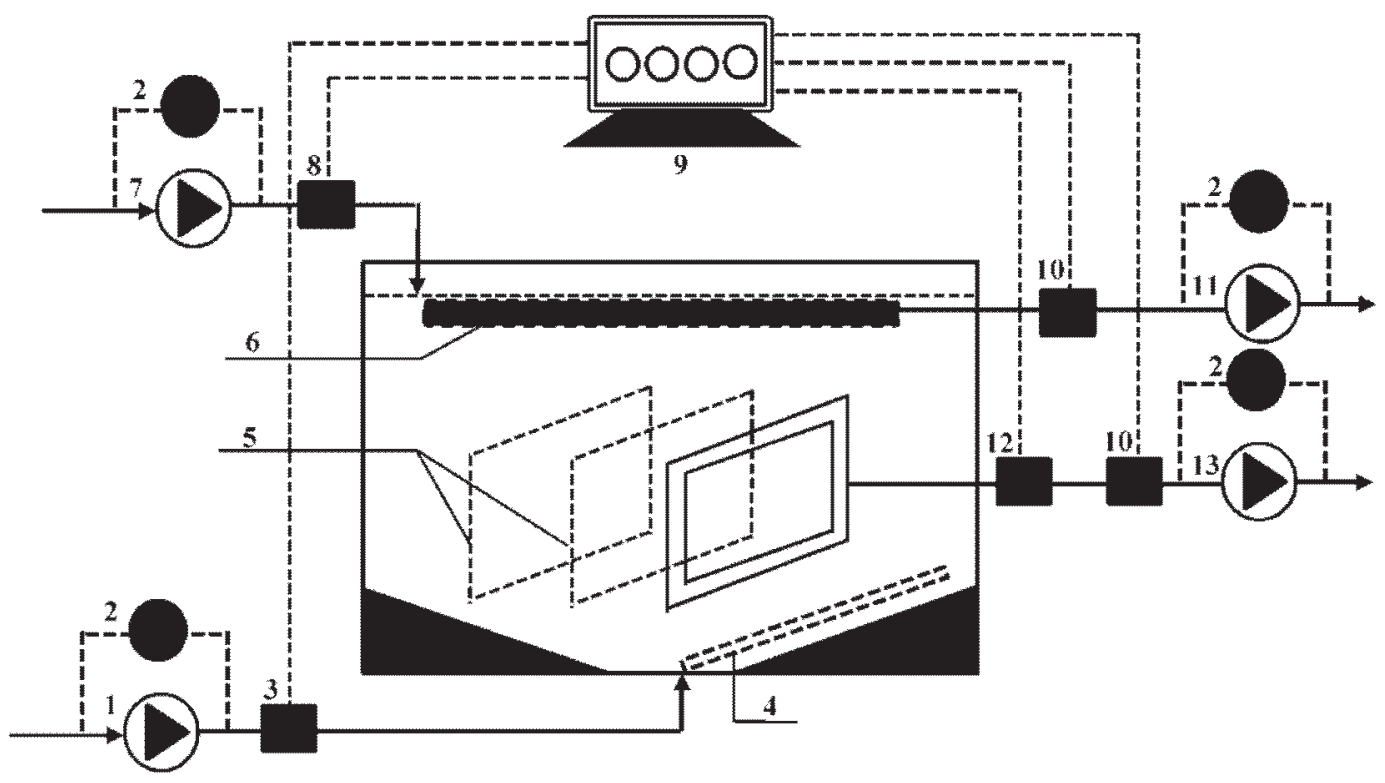

Fig. 2. A diagram of SMBR system used for experimental study.

1-aeration pump, 2-timer, 3-gas flow sensor, 4-aeration gadget, 5-partition plate, 6-supernatant drainage gadget, 7-wastewater feeding pump, 8-inlet flow sensor, 9-data processing and controlling system, 10-flow sensor, 11-supernatant drainage pump, 12-pressure sensor, 13-membrane filtration pump. 
plant. The typical parameters of SBR operation were as follows. The time for feeding, aeration, settling, discharging and idling was 3 mins, 224 mins, 5 mins, 6 mins and $1 \mathrm{~min}$ at a cycle of four hours, respectively. In addition, those parameters would be adjusted appropriately according to the variation of SVI during SBR operation. The sludge remained in the bucket was continuously cultivated for SMBR usage while the nutrient solution was changed from the synthetic wastewater to the treated wastewater. SMBR systems with the internal circulation consisted of three parts, flat membrane module and automatic control section as well as data processing both for the activated sludge and granular sludge, respectively. The other parts mainly included supernatant drainage gadget, partition plate, aeration device, reaction tank. The automatic control system included pumps for wastewater inlet, aeration, supernatant drainage and membrane filtration, sensors for air and water as well as pressure, timers. The structure of submerged membrane granular sludge bioreactor (SMGSBRs) was the same with submerged membrane activated sludge bioreactor (SMASBRs).

\section{Results and Discussion}

\section{Cultivation of Activated and Granular-Like Aerobic Sludge}

The macro-morphology of the original, acclimated and granular-like aerobic sludge was shown in Fig. 3, respectively. Comparing to the fresh sludge, i.e. the original activated sludge taken from the local water reclamation plant, the three weeks acclimated activated sludge had a silky and sponge-like appearance. It also indicated the harvested granular-like aerobic sludge cultivated one month in SBR had a relatively uniform size (Fig. 3). This implied that the activated sludge was firstly acclimated under certain conditions in tank with synthetic wastewater and then the industrial biopharmaceutical wastewater, which could make the activated sludge better adapt the cultivated environment. The appropriate SBR operation parameters could be reasonably optimized through monitoring SVI of the mixed activated sludge. Therefore, the granular-like aerobic sludge could be prepared quickly in SBR, which provided the basis for the preparation of the granularlike aerobic sludge in large-scale and its industrial application.

Size distribution analysis showed that the average radius $\left(D_{50}\right)$ for the cultivated activated sludge and the granular-like aerobic sludge was about $52.3 \mu \mathrm{m}$ and $741.7 \mu \mathrm{m}$, respectively, which indicated the average diameter of the granular-like aerobic sludge was about 14 times larger than the cultivated activated sludge. The difference in particle size between the cultivated activated sludge and the granular-like aerobic sludge would probably impact SMBR operation and performance.

\section{SMBRs Performance with Cultivated and Granular-Like Aerobic Sludge}

The performance of SMBRs with the cultivated activated sludge and the granular-like aerobic sludge was preliminarily investigated in this study in terms of membrane flux, removal of $\mathrm{COD}$ and $\mathrm{NH}_{4}^{+}-\mathrm{N}$, the variation of MLSS, and the residual of $\mathrm{COD}, \mathrm{NH}_{4}^{+}-\mathrm{N}$, $\mathrm{NO}_{2}^{-}-\mathrm{N}, \mathrm{NO}_{3}^{-} \mathrm{N}$ in the filtrate of SMBRs. In addition, typical samples of the residual of $\mathrm{TN}$ and $\mathrm{TP}$ for the treated wastewater were also analyzed to compare the performance of SNDPR between SMBRs with the cultivated activated sludge and the granular-like aerobic sludge, respectively.

SMBRs permeate flux at concentration of $1250 \mathrm{mg} / \mathrm{L}$ MLSS for the cultivated activated and granular-like aerobic sludge were shown in Fig. 4, respectively. It indicated that even MLSS was at such low concentration, the permeate flux in granular-like aerobic sludge was slightly higher than the acclimated activated sludge in SMBR system, while the permeate flux for SMBR systems was lower than the pure water system.

Therefore, filtration tests with relatively higher MLSS concentration $(8200 \mathrm{mg} / \mathrm{L})$ were carried out in this study for acclimated activated sludge and granular-like aerobic sludge in SMBR systems,
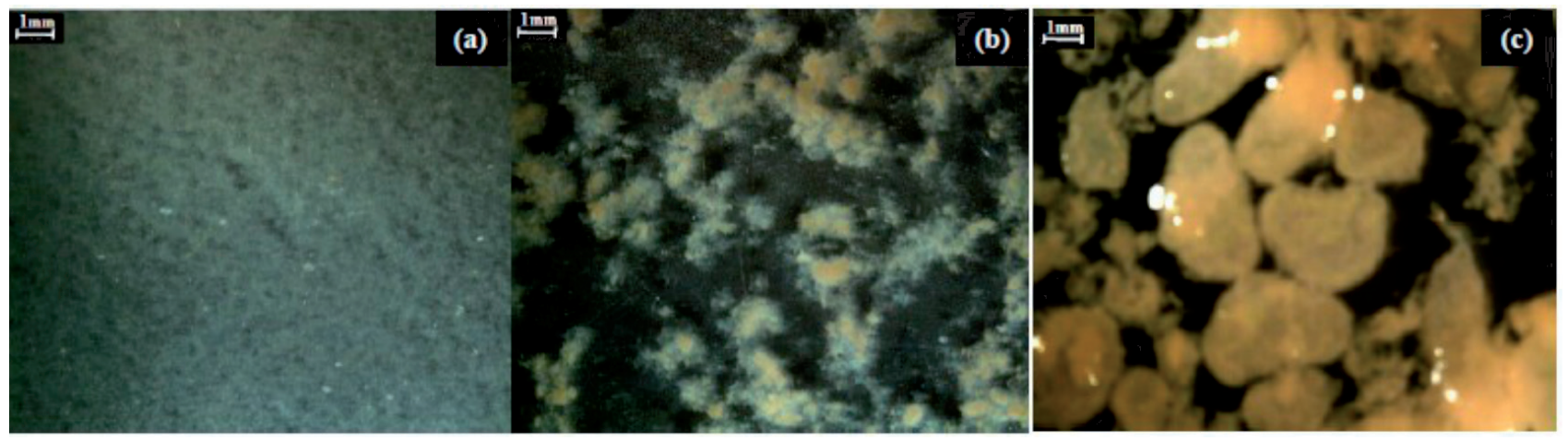

Fig. 3. Morphology of the original, cultivated and harvested granular-like aerobic sludge: a) original activated sludge b) cultivated activated sludge c) granular-like aerobic sludge. 


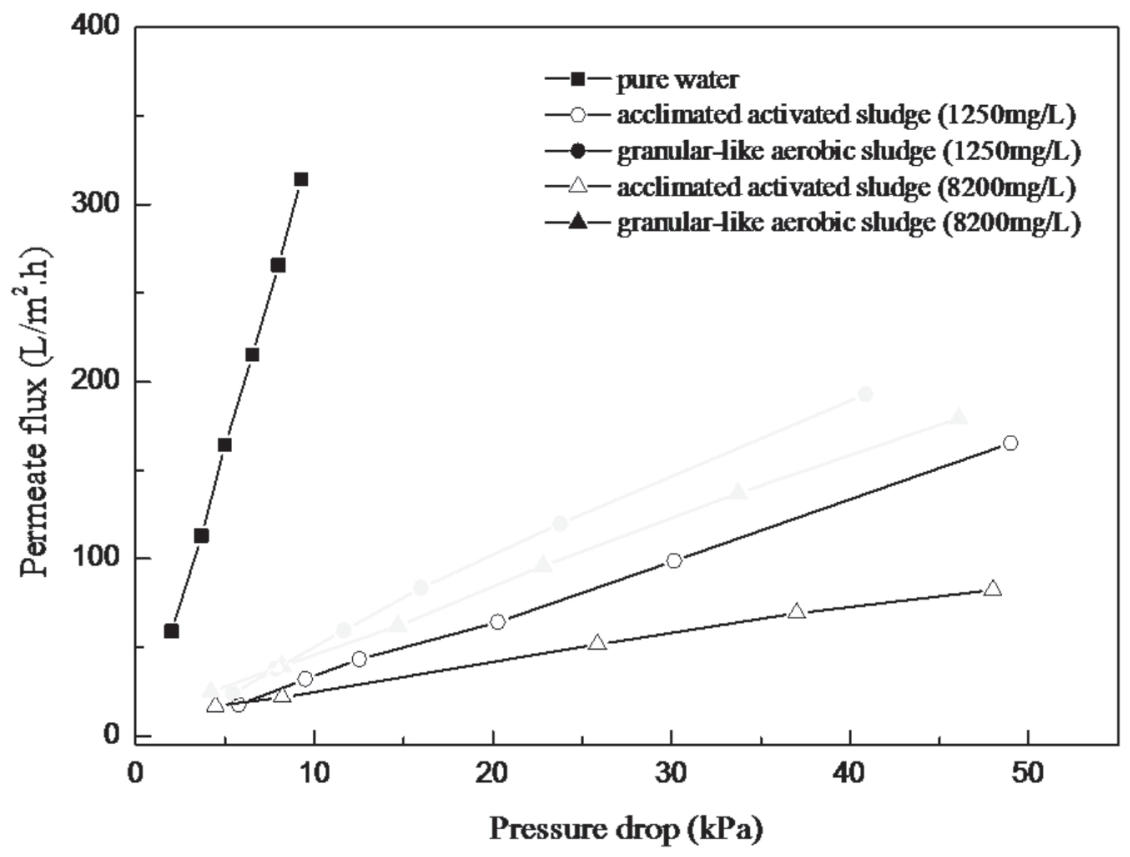

Fig. 4. The permeate flux for cultivated activated and granular-like aerobic sludge in SMBRs.

respectively. Results indicated the permeate flux of the granular-like aerobic sludge was obviously higher than the acclimated activated sludge, which also showed that it was less affected by MLSS concentration for SMBR with granular-like aerobic sludge. This implied that membrane fouling occurred in SMBR system could be better alleviated by using the granular-like aerobic sludge under the used experimental conditions. Concentrations of $\mathrm{COD}$ and $\mathrm{NH}_{4}^{+}-\mathrm{N}$ of the wastewater fed to SMBRs were around $1030 \mathrm{mg} / \mathrm{L}$ and $60 \mathrm{mg} / \mathrm{L}$, respectively, and MLSS in SMBRs for the acclimated activated sludge and granular-like aerobic sludge was around $8700 \mathrm{mg} / \mathrm{L}$ (Fig. 5), which indicated SMBR systems were well operated and those collected data were reasonable.

The residual of COD, $\mathrm{NH}_{4}^{+}-\mathrm{N}, \mathrm{NO}_{2}^{-}-\mathrm{N}$ and $\mathrm{NO}_{3}^{-}-\mathrm{N}$ in filtrate for acclimated activated sludge and granularlike aerobic sludge in SMBR systems was shown in Fig. 6, respectively. It showed the residual of COD, $\mathrm{NH}_{4}^{+}-\mathrm{N}, \quad \mathrm{NO}_{2}^{-}-\mathrm{N}$ and $\mathrm{NO}_{3}^{-}-\mathrm{N}$ for the acclimated

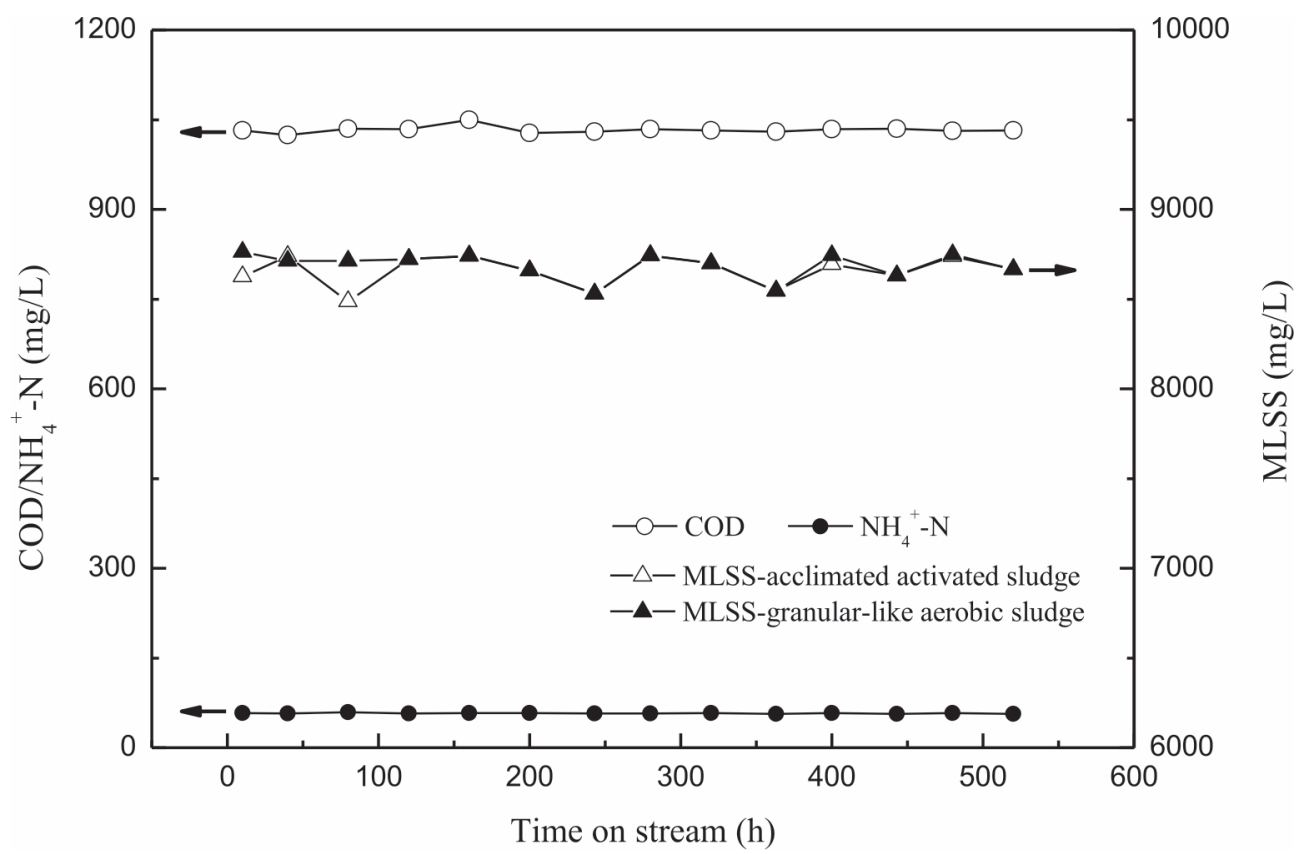

Fig. 5. The variation of concentration of MLSS, COD and $\mathrm{NH}_{4}^{+}-\mathrm{N}$ of the treated wastewater in SMBRs, respectively. 


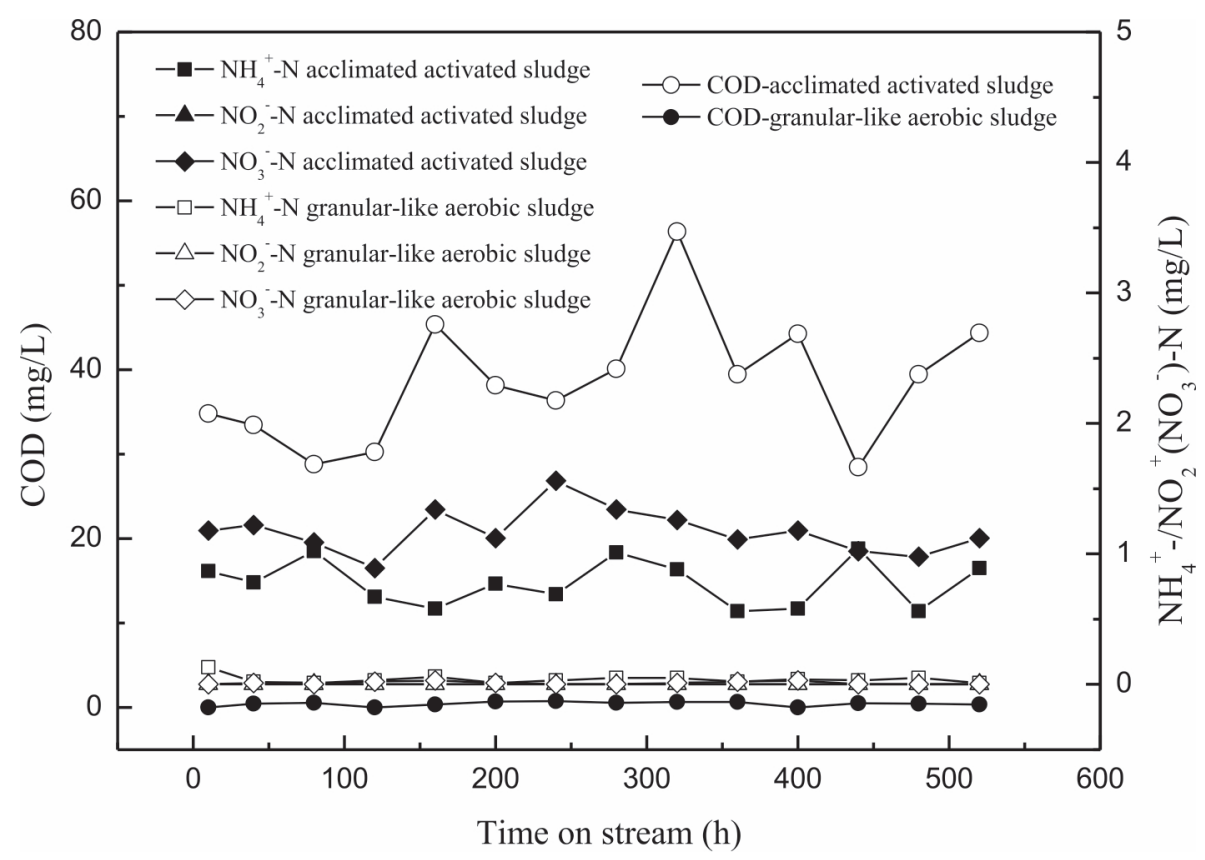

Fig. 6. The residual of $\mathrm{COD}, \mathrm{NH}_{4}^{+}-\mathrm{N}, \mathrm{NO}_{2}^{-}-\mathrm{N}$ and $\mathrm{NO}_{3}^{-}-\mathrm{N}$ in filtrate with acclimated activated sludge and granular-like aerobic sludge in SMBRs, respectively.

activated sludge SMBR was 30 60 mg/L, 0.5 1.2 mg/L, 0 , and $0.8 \sim 2.0 \mathrm{mg} / \mathrm{L}$, respectively, while for the granular-like aerobic sludge SMBR was $0 \sim 1.0 \mathrm{mg} / \mathrm{L}$, $0 \sim 0.2 \mathrm{mg} / \mathrm{L}, 0$, and $0 \sim 0.03 \mathrm{mg} / \mathrm{L}$, respectively. Typical analytical data also showed that the removal efficiencies of TN and TP were $32.86 \%, 99.52 \%$ and $17.54 \%, 77.68 \%$ for acclimated activated sludge and granular-like aerobic sludge SMBR systems, respectively. In addition, it did not show obvious stratification or crush of the granular-like aerobic sludge in SMBR with a size of $0.5 \sim 0.8 \mathrm{~mm}$ during the operation, which could be regarded as the most suitable granular size for granular-like aerobic sludge in this experiment with consideration of its perspective of COD, denitrification and phosphorus removal. The preliminary results clearly showed that the granular-like aerobic sludge SMBR system was more efficient than the acclimated activated sludge under experimental conditions and it provided the basis for a pilot-scale experimental investigation.

\section{SMBRs Stability Evaluation}

Results in Fig. 5 showed the difference of performance on permeate flux between the acclimated activated sludge and the granular-like aerobic sludge SMBRs would likely be due to the increase of biomass concentration. This implied that the membrane fouling propensity was apparently lower in granular-like aerobic sludge SMBR without membrane cleaning during the operation, which indicated that it could be effective and stable for biopharmaceutical wastewater treatment during long-term operation. This was further clarified by the filtration stability testing (Fig. 7). The stability was tested under continuous operation in SMBRs with the following conditions, $45.0 \mathrm{~L} / \mathrm{m}^{2}$.h for flux, $3.2 \mathrm{~L} / \mathrm{min}$ for air flow rate and $7850 \sim 8200 \mathrm{mg} / \mathrm{L}$ for biomass concentration, respectively.

The permeate flux in the acclimated activated sludge SMBR rapidly declined by about $50 \%, 70 \%$ and $90 \%$ when operation around $30 \mathrm{~h}, 150 \mathrm{~h}$ and $320 \mathrm{~h}$, while the permeate flux in the granular-like aerobic sludge SMBR only declined by about $7.0 \%, 7.8 \%$ and $8.3 \%$ when operation around $30 \mathrm{~h}, 160 \mathrm{~h}$ and $310 \mathrm{~h}$, respectively. The permeate flux in the granular-like aerobic sludge SMBR was quite stable compared with the acclimated activated sludge SMBR, which clearly showed potential advantages of the granular-like aerobic sludge over the acclimated activated sludge on membrane fouling control in SMBR. At the end of the operation, the membrane modules were removed from the SMBR systems. Part of the dismounted membranes was only physically cleaned. The fresh and used membranes in SMBR systems were subjected to SEM observation for comparison (Fig. 8). It indicated that the surface of membrane used in SMBR with the granular-like aerobic sludge was almost the same with the fresh membrane, while the surface of membrane used in SMBR with acclimated activated sludge clearly reflected the relative quantities of the different foulants on the membrane, which was the main reason resulted in the permeate flux rapidly declined in SMBR system with the operation time (Fig. 7). Further studies on molecular aspects of granulation in SBR and maximizing the benefits of the granular-like aerobic sludge in SMBR for widespread implementation of achieving this emerging technology in sustainable biopharmaceutical wastewater treatment were necessary. 


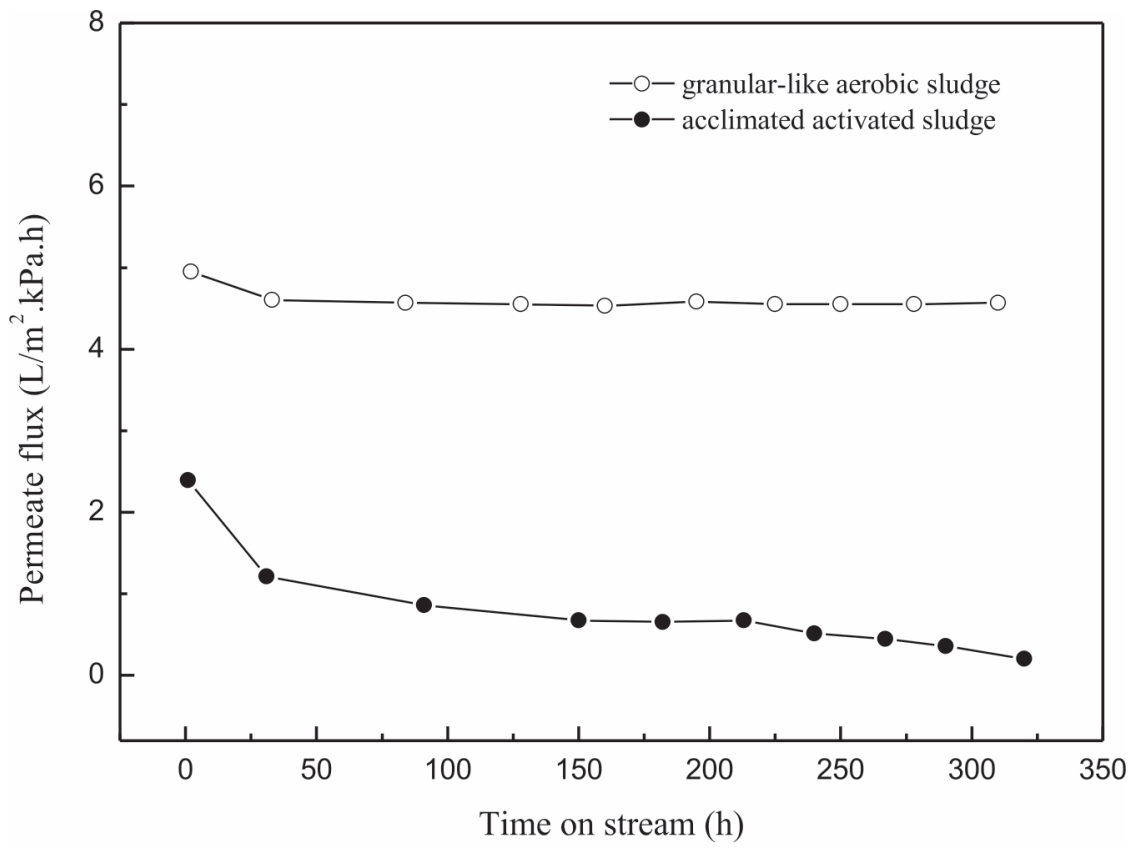

Fig. 7. The variation of permeate flux based on unit pressure on stability with acclimated activated sludge and granular-like aerobic sludge in SMBRs.
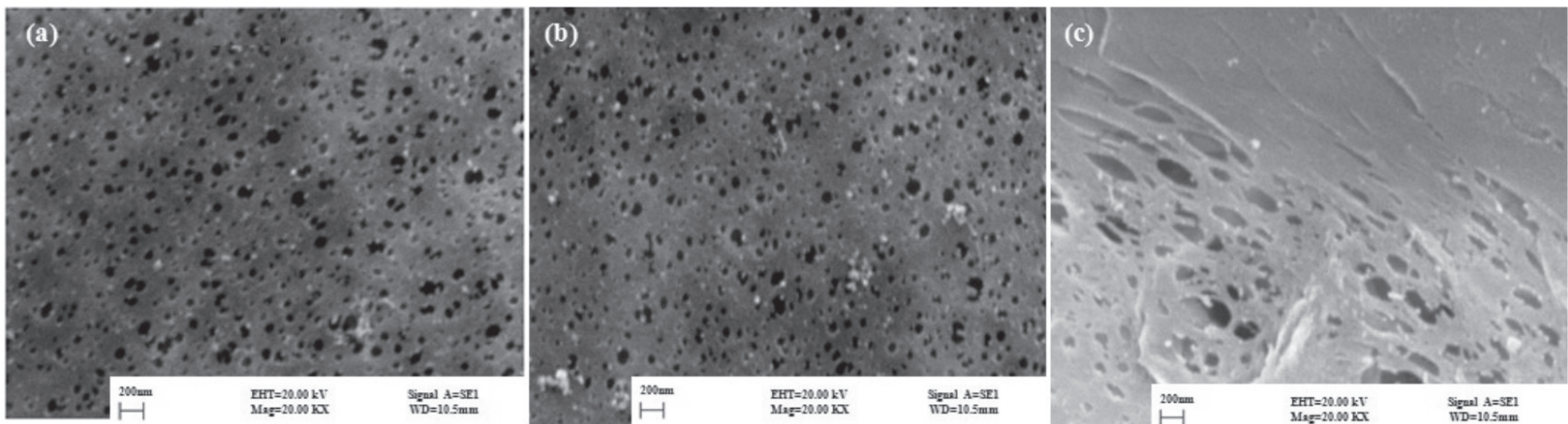

Fig. 8. SEM images of the fresh and used membranes in SMBR systems: a) fresh membrane b) SMBR used with granule sludge c) SMBR used with activated sludge.

\section{Conclusions}

The cultivation and granulation of aerobic granules in the airlift SBR by using the acclimated activated sludge and real biopharmaceutical wastewater was studied, which indicated that the granular-like aerobic sludge was quickly prepared through firstly three weeks cultivating the activated sludge in tank with synthetic wastewater and then one month in airlift sequencing batch reactor (SBR) with real biopharmaceutical wastewater by reasonably optimizing operation parameters based on the variation of sludge volume index (SVI). It clearly showed that the performance of granular-like aerobic sludge SMBR system was better than the acclimated activated sludge SMBR system. Results related to the wastewater treatment indicated the residual of $\mathrm{COD}, \mathrm{NH}_{4}^{+}-\mathrm{N}, \mathrm{NO}_{2}^{-}-\mathrm{N}$ and
$\mathrm{NO}_{3}^{-}-\mathrm{N}, \mathrm{TN}$ and $\mathrm{TP}$ in filtrate with granular-like aerobic sludge SMBR was much lower than the acclimated activated sludge SMBR system under the same used experimental conditions. SEM observation indicated that the surface of membrane used in SMBR with the granular-like aerobic sludge was almost the same with the fresh membrane, while the surface of membrane used in SMBR with acclimated activated sludge clearly reflected the relative quantities of the different foulants on the membrane, which probably was the main reason resulted in the permeate flux rapidly declined in SMBR system with the operation time. This research would provide the basis for further investigation on SMGSBRs in a pilot-scale for widespread implementation of this emerging technology in sustainable biopharmaceutical wastewater treatment. 


\section{Acknowledgments}

This work was supported by the Tianjin Yao Tech Co., Ltd., China. The authors warmly thank Ms. Linqi Wang for her valuable contribution during the paper preparation.

\section{Conflict of Interest}

The Authors declare no conflict of interest.

\section{References}

1. DE BRUIN L.M.M., DE KREUK M.K., VAN DER ROEST H.F.R., UIJTERLINDE C., VAN LOOSDRECHT M.C.M. Aerobic granular sludge technology: An alternative to activated sludge. Water Sci. Technol. 49, 1, 2004.

2. LIÉBANA R., MODIN O., PERSSON F., WILÉN B.M. Integration of aerobic granular sludge and membrane bioreactors for wastewater treatment. Crit. Rev. Biotechnol. 38, 801, 2018.

3. SHOW K.Y., LEE D.J., TAY J.H. Aerobic granulation: Advances and challenges. App. Biochem. Biotech. 167, 1622, 2012.

4. MORALES N., FIGUEROA M., FRA-VÁZQUEZ A., VAL DEL RÍO A., CAMPOS J.L., MOSQUERA-CORRAL A., MÉNDEZ R. Operation of an aerobic granular pilot scale SBR plant to treat swine slurry, Process Biochem. 48, 1216, 2013.

5. BENGTSSON S., DE BLOIS M., WILÉN B.M., GUSTAVSSON D. Treatment of municipal wastewater with aerobic granular sludge. Crit. Rev. Environ. Sci. Technol. 48, 119, 2018.

6. NANCHARAIAH Y.V., SARVAJITH M. Aerobic granular sludge process: a fast growing biological treatment for sustainable wastewater treatment. Curr. Opin. Environ. Sci. Health 12, 57, 2019.

7. TAYÀ C., GUISASOLA A., BAEZA J.A. Assessment of bioaugmentation strategy with polyphosphate accumulating organisms in a nitrification/denitrification sequencing batch reactor. Bioresour. Technol. 102, 7678, 2011.

8. ZOUBOULIS A.I., GKOTSIS P.K., ZAMBOULIS D.X., MITRAKAS M.G. Application of powdered activated carbon (PAC) for membrane fouling control in a pilot-scale MBR system. Water Sci. Technol. 75, 2350, 2017.

9. GKOTSIS P.K., BATSARI E.L., PELEKA E.N., TOLKOU A.K., ZOUBOULIS A.I. Fouling control in a lab-scale MBR system: Comparison of several commercially applied coagulants. J. Environ. Manage. 203, 838, 2017.

10. 1FAN H., XIAO K., MU S., ZHOU Y., MA J., WANG X., HUANG X. Impact of membrane pore morphology on multi-cycle fouling and cleaning of hydrophobic and hydrophilic membranes during MBR operation. J. Membr. Sci. 556, 312, 2018.

11. JIANG C.K., TANG X., TAN H., FENG F., XU Z.M., MAHMOOD Q., ZENG W.Z., MIN X.B., TANG C.J. Effect of scrubbing by $\mathrm{NaClO}$ backwashing on membrane fouling in anammox MBR. Sci. Total Environ. 670, 149, 2019.

12. KIMURA K., KAKUDA T., IWASAKI H. Membrane fouling caused by lipopolysaccharides: a suggestion for alternative model polysaccharides for MBR fouling research. Sep. Purif. Technol. 223, 224, 2019.

13. DU X., SHI Y., JEGATHEESAN V., HAQ I.U. A Review on the mechanism, impacts and control methods of membrane fouling in MBR system. Membranes 10, 24, 2020.

14. GKOTSIS P., PELEKA E., ZOUBOULIS A. The use of natural minerals in a pilot-scale MBR for membrane fouling mitigation. Separations 7, 24, 2020.

15. SAJJAD M., KIM I.N.S., KIM K.S. Development of a novel process to mitigate membrane fouling in a continuous sludge system by seeding aerobic granules at pilot plant. J. Membr. Sci. 497, 90, 2016.

16. IORHEMEN O.T., HAMZA R.A., TAY J.H. Utilization of aerobic granulation to mitigate membrane fouling in MBRs. Membr. Water Treat. 8, 395, 2017.

17. IORHEMEN O.T., HAMZA R.A., ZAGHLOUL M.S., TAY J.H. Simultaneous organics and nutrients removal in side-stream aerobic granular sludge membrane bioreactor (AGMBR). J. Water Process. Eng. 21, 127, 2018.

18. MCSWAIN B.S., IRVINE R.L., WILERER P.A. The effect of intermittent feeding on aerobic granule structure. Water Sci. Technol. 49, 19, 2004.

19. LIU Y., TAY J.H. State of the art of biogranulation technology for wastewater treatment. Biotechnol. Adv. 22, 533, 2004.

20. MCSWAIN B.S., IRVINE R.L., HAUSNER M., WILDERER P. Composition and distribution of extracellular polymeric substances in aerobic flocs and granular sludge. Appl. Environ. Microbiol. 71, 1051, 2005.

21. GAO D., YUAN X., LIANG H., WU W.M. Comparison of biological removal via nitrite with real-time control using aerobic granular sludge and flocculent activated sludge. Appl. Microbiol. Biotechnol. 89, 1645, 2011.

22. COMA M., VERAWATY M., PIJUAN M., YUAN Z., BOND P.L. Enhancing aerobic granulation for biological nutrient removal from domestic wastewater. Bioresource Technol. 103, 101, 2012.

23. PRONK M., DE KREUK M., DE BRUIN B., KAMMINGA P., KLEEREBEZEM R.V., VAN LOOSDRECHT M. Full scale performance of the aerobic granular sludge process for sewage treatment. Water Res. 84, 207, 2015.

24. CAMPO R., DI BELLA G. Petrochemical slop wastewater treatment by means of aerobic granular sludge: effect of granulation process on bio-adsorption and hydrocarbons removal. Chem. Eng. J. 378, 122083, 2019.

25. LI Z.H., ZHU Y.M., ZHANG Y.L., ZHANG Y.R., HE C.B., YANG C.J. Characterization of aerobic granular sludge of different sizes for nitrogen and phosphorus removal. Environ. Technol. 40, 3622, 2019.

26. LI Y., LIU S.J., CHEN F.M., ZUO J.E. Development of a dynamic feeding strategy for continuous-flow aerobic granulation and nitrogen removal in a modified airlift loop reactor for municipal wastewater treatment. Sci. Total Environ. 714, 136764, 2020.

27. RAJITHA K., SARVAJITH M., VENUGOPALAN V.P., NANCHARAIAH Y.V. Development and performance of halophilic microalgae-colonized aerobic granular sludge for treating seawater-based wastewater. Bioresource Technol. Reports 11, 100432, 2020.

28. HE Q.L., WANG H.Y., CHEN L., GAO S.X., ZHANG W., SONG J.Y., YU J. Elevated salinity deteriorated enhanced biological phosphorus removal in an aerobic granular sludge sequencing batch reactor performing simultaneous nitrification. denitrification and phosphorus removal. J. Hazard. Mater. 390, 121782, 2020. 
29. IORHEMEN O.T., ZAGHLOUL M.S., HAMZA R.A., TAY J.H. Long-term aerobic granular sludge stability through anaerobic slow feeding, fixed feast-famine period ratio, and fixed SRT. J. Environ. Chem. Eng. 8, 103681, 2020.

30. HE Q.L., SONG J.Y., ZHANG W., GAO S.X., WANG H.Y., YU J. Enhanced simultaneous nitrification, denitrification and phosphorus removal through mixed carbon source by aerobic granular sludge. J. Hazard. Mater. 382, 121043, 2020.

31. GAO S.X., HE Q.L., WANG H.Y. Research on the aerobic granular sludge under alkalinity in sequencing batch reactors: Removal efficiency, metagenomic and key microbes. Bioresource Technol. 296, 122280, 2020.

32. EN WE A.C., ARIS A., ZAIN N.A.M., MUDA K., SULAIMAN S. Influence of static mixer on the development of aerobic granules for the treatment of lowmedium strength domestic wastewater. Chemosphere 263, 128209, 2021.
33. JI L., ZHOU J.T. Influence of aeration on microbial polymers and membrane fouling in submerged membrane bioreactors. J. Membr. Sci. 276, 168, 2006.

34. LI J.F., LIU Y.J., LI X.N., CHENG F.Q. Reactor performance and membrane fouling of a novel submerged aerobic granular sludge membrane bioreactor during longterm operation. J. Water Reuse Desal. 9, 1, 2019.

35. GUO H.X., FELZ S., LIN Y.M., VAN LIER J.B., DE KREUK M. Structural extracellular polymeric substances determine the difference in digestibility between waste activated sludge and aerobic granules. Water Res. 181, 115924, 2020.

36. WANG Y.Y., CHEN Q.W., LIN Y.X., SU K.Z., HAO T.W., LIU L., SHENG G.P. Performance enhancement of a submerged forward osmotic membrane bioreactor by aerobic granules. Sep. Purif. Technol. 254, 117608, 2021. 